search efforts to concentrate on teaching undergraduates. Such a decoupling of research and teaching functions would represent a significant departure from the traditional university role, but Smith and Karlesky note that some university departments are already contemplating whether to continue as research centres.

One of the major findings of the study was that recent trends in funding and enrolments have been felt most keenly by less distinguished departments and by less distinguished investigators. "In contrast", Smith and Karlesky report, "the leading science departments have tended to retain their relative strength ... the downward trend has not appeared uniformly throughout all second-rank institutions, and the indicators of trouble have not always reached an advanced state. But the signs are sufficiently clear to warrant the conclusion that a very rapid deterioration in the relative position of many weaker departments could well occur in the near future".

In a sense, Smith and Karlesky note, it is "highly reassuring that our system of awarding research grants and contracts according to scientific merit appears to have achieved its aim in making certain that pre-eminent investigators are able to continue their work, and in most cases with adequate support". Nevertheless, the increased stratification in university research departments and the possibility that some second-rank institutions will drop research all together, raises a number of fundamental questions.

Although PhD programmes probably over expanded during the 1960s and "some of the research undertaken a decade ago was of less than first-rank quality", how far should the drift toward fewer and fewer outstanding research departments be allowed to proceed? Smith and Karlesky argue that "it is possible that the competitive elements in the system could be undermined if there were too few universities fully equipped for pre-eminent research. The nation would then be forced to rely on a narrow base of dominant centers".

In any case they argue that the trend "towards fewer universities and departments able to mount first-class research efforts will continue so long as federal research support remains essentially level, which is likely to be the case to some extent. Universities may be able to preserve their research missions by achieving a functional division of labor among themselves and by developing highly specialised research programs. But there is a certain minimum coverage of basic science fields that a university must undertake to retain its research vitality".

\title{
200-mile zones: the threat to marine science
}

As THE sixth session of the gruelling Law of the Sea Conference opened in New York last week, the National Academy of Sciences warned that the latest draft treaty could "cripple" marine scientific research. The Academy's warning, contained in a letter sent to Elliot Richardson, head of the US delegation to the conference, claimed that oceanographic research is in fact already being seriously hampered by restrictions imposed by some coastal nations.

The chief concern is that the draft treaty now under discussion (called the Revised Single Negotiating Text, in United Nations parlance) would give coastal states the right to regulate scientific research conducted within 200 miles of their shores. Since the coastal regions contain some of the most interesting oceanographic pheno. mean, such as the major currents, virtually all of the oceans' biological activity and most of the world's undersea earthquakes, the Academy is worried that the treaty could put major areas of scientific research offlimits.

The revised single negotiating text would require that the consent of a coastal state be obtained before a research project is conducted within 200 miles of its shore. Consent could be denied for research which "bears substantially on the exploration of the living and non-living resources", involves drilling, or interferes with fishing or other economic activities. In addition, the coastal state would have the power to veto publication of research results from some types of projects, and it would have the right to halt a project if it believed that the research differed from the description given in the original proposal. Such restrictions could "cripple future marine scientific research which will be critical to the survival of the oceans and mankind", the Academy stated.

The Academy is therefore urging that the draft be modified to provide the following conditions for research projects conducted outside a nation's territorial water (which will probably be 12 miles), but inside the 200 -mile 'Economic Zone':

- Freedom of research should be guaranteed except for carefully specifield and limited types of projects.

- Specific criteria should determine whether or not a project requires prior consent, and a definite procedure shculd be established for obtaining consent. The chief objective would be to ensure that no unreasonable or arbitrary restrictions are imposed.

- Freedom to publish and disseminate research results should be preserved.

In addition, the Academy recommends that the nation undertaking the research should be required to keep the coastal state fully informed of the nature, objective and schedule of a proposed project. The coastal state should also have a right to be represented in the project, and it should be given preliminary and final reports, a share in the data and samples, and assistance in interpreting the results.

To support its contention that the provisions contained in the draft treaty would seriously hamper research, the Academy cites evidence that a number of coastal states are already exercising strict controls over projects within 200 miles of their shores. In particular the Academy notes that "in the past year the records of the US National University Oceanic Laboratory System, which coordinates the activities of the academic fleet, indicate that about half of the scheduled cruises for work in waters over which other nations claim control have been cancelled because requests were denied, or have been hindered sufficiently to prevent the cruise taking place. Some requests were never acknowledged; sometimes approval came too late for the program to be successfully conducted. At least 18 nations were involved in one way or another in inhibiting science in this way".

In spite of the Academy's strong plea, oceanographers do not hold much hope that the final version of the Law of the Sea Treaty (if such a document ever emerges) will protect marine research from arbitrary or unreasonable restrictions. Coastal states sometimes claim that research vessels are used as a cover for military or commercial operations and their activities should therefore be tightly monitored and controlled. Moreover, since the oceanographic research fleet belongs almost exclusively to the developed countries, there's little immediate incentive for developing countries to grant freedom of research within their economic zones.

Colin Norman 